\title{
Persistence and Compliance with Pazopanib in Patients with Advanced Renal Cell Carcinoma Within a U.S. Administrative Claims Database
}

\author{
Michelle D. Hackshaw, BScPharm, MSHS, PhD; Saurabh P. Nagar, BPharm, MS; \\ Daniel C. Parks, MS, PhD; and Lesley-Ann N. Miller, MS, PhD
}

\section{ABSTRACT}

BACKGROUND: Pazopanib is an oral tyrosine kinase inhibitor with demonstrated efficacy and tolerability in patients with advanced renal cell carcinoma (RCC).

OBJECTIVE: To examine pazopanib persistence and compliance (adherence) and other drug utilization patterns in both treatment-naïve (first-line) patients and those previously treated with RCC therapy in the real-world setting. Key factors affecting persistence and compliance were also explored.

METHODS: This was a retrospective claims analysis using the Truven Health MarketScan Databases to cover claims activity from October 2007 through March 2012. Patients with advanced RCC aged $\geq 18$ years who had received pazopanib with 180 days of follow-up were included. Bivariate comparisons of results from first-line and previously treated patients with RCC were conducted. Pazopanib persistence was measured using (a) estimated level of persistence with therapy (ELPT; i.e., the percentage of patients remaining on therapy at 30,60 , and 90 days [patients were censored at 180 days]); (b) time to discontinuation (i.e., duration of therapy); and (c) proportion of days covered (PDC; i.e., the ratio of [total days drug available minus days' supply of last prescription] to [last prescription date minus first prescription date]). Compliance was measured by medication possession ratio (MPR; i.e., the ratio of [total days' supply minus days' supply of last prescription] to [last prescription date minus first prescription date]). Other drug utilization measures included days' supply, time to initiation, time to switching, and dose-related measures. Random forest models were used to explore key factors of pazopanib persistence and compliance.

RESULTS: A total of 143 patients met all inclusion criteria; $43.3 \%$ were treated with pazopanib first line (first-line cohort), and $56.6 \%$ had $\geq 1$ prior lines of therapy (previously treated cohort). The mean ( \pm standard deviation [SD]) age of patients was $62.9( \pm 10.3)$ years, and $71.3 \%$ of them were males. Continuous pazopanib therapy for up to 90 days was observed in $>50 \%$ of patients in both cohorts. In the first-line cohort, ELPT at 30,60 , and 90 days was $98.39 \%, 70.97 \%$, and $56.45 \%$, respectively; the mean $( \pm \mathrm{SD})$ number of days to discontinuation was $112.2( \pm 62.8)$; the mean $( \pm$ SD) PDC was $84.7 \%( \pm 16.7 \%)$; and the mean $( \pm S D)$ MPR was $85.2 \%$ $( \pm 16.9 \%)$. Similar results were observed in the previously treated population: ELPT at 30,60 , and 90 days was $98.77 \%, 75.31 \%$, and $58.02 \%$, respectively; the mean $( \pm S D)$ number of days to discontinuation was 118.7 $( \pm 61.4)$; the mean $( \pm S D)$ PDC was $87.8 \%( \pm 13.5 \%)$; and the mean $( \pm S D)$ MPR was $90.1 \%( \pm 13.9 \%)$. Differences between the 2 cohorts were not statistically significant. More than $90 \%$ of patients in both cohorts had at least a 30 -day supply of therapy $(91.9 \%$ of first-line versus $90.2 \%$ of previously treated; $P=0.153)$. The mean $( \pm \mathrm{SD})$ time from metastatic diagnosis to start of pazopanib therapy was $104.7( \pm 199.3)$ days in the first-line cohort and $360.9( \pm 187.0)$ days in previously treated patients $(P=0.001)$. Forty-six patients switched to another therapy: 17 patients in the first-line cohort and 29 patients in the previously treated cohort; the mean $( \pm$ SD) time to switching therapy from each cohort was $94.7( \pm 41.4)$ days and 87.8 $( \pm 49.6)$ days $(P=0.146)$, respectively. Statistically significant differences were observed for the starting and ending doses between the 2 cohorts. The average daily dosage of pazopanib was $>700 \mathrm{mg}$ in both cohorts $(P=0.055)$, with a maximum dose of $800 \mathrm{mg}$. Random forest models demonstrated that younger age and higher comorbidity predicted both higher persistence and compliance.

CONCLUSIONS: In this observational study, $>50 \%$ of patients with advanced RCC were on pazopanib for almost 4 months, with the majority of both cohorts achieving high persistence and high compliance. Additionally, younger age and higher comorbidity index were the strongest predictors of both greater persistence and compliance. Further studies with larger cohorts and longer follow-up are needed to validate these findings.

J Manag Care Pharm. 2014;20(6):603-10

Copyright $\odot 2014$, Academy of Managed Care Pharmacy. All rights reserved.

\section{What is already known about this subject}

The few U.S. studies of treatment patterns with oral, targeted anticancer agents in patients with advanced renal cell carcinoma (RCC) mostly reported results of patients receiving sunitinib or sorafenib. The tyrosine kinase inhibitor pazopanib was approved by the FDA in 2009 for treatment of patients with advanced RCC, but there is little information available on patient persistence and adherence outside of clinical trials.

\section{What this study adds}

Given the importance that oral cancer therapies play in specialty care, this study adds to the gap in the literature regarding persistence/compliance with oral oncolytics outside of the clinical trial setting.

Drug utilization and treatment patterns among patients who received pazopanib as treatment for advanced RCC outside the clinical trial setting showed that more than one-half of patients were on pazopanib for almost 4 months and were both persistent and compliant. 
$\mathrm{I}$ n 2013, it was estimated that kidney cancer would account for approximately $3 \%$ to $5 \%$ of all cancers in the United States, with 65,150 new cases and 13,680 deaths expected., ${ }^{1,2}$ Until 2005, cytokine therapy had been the only approved standard initial therapy for treating advanced renal cell carcinoma (RCC) postsurgery. These treatments are associated with high toxicities and offer limited clinical benefit to selected patients. ${ }^{3,4}$ Recent therapeutic advances have led to novel targeted therapies for patients with advanced RCC, which include mammalian target of rapamycin inhibitors, the monoclonal antibody bevacizumab, and tyrosine kinase inhibitors (TKIs). ${ }^{4}$

Pazopanib (Votrient), approved by the U.S. Food and Drug Administration in October 2009, is an orally available, multitargeted TKI that has demonstrated efficacy and acceptable tolerability in 2 phase 11 clinical trials of advanced/metastatic RCC., 5 Pazopanib is dosed continuously as 800 milligrams (mg; four $200 \mathrm{mg}$ tablets) once daily. ${ }^{7}$

There has been an increased use of specialty drugs within oncology. 8 Although many of these drugs may come with a high cost, oncologists are more likely to prescribe them over intravenous drug regimens as they pay more attention to patient preferences and quality-of-life issues and to the convenience and flexibility that oral treatment options can provide for patients, while also taking advantage of the availability of specialty pharmacies. However, dosing and adherence to these treatments outside of the clinical trial setting has not been well studied, and may be lower than that in clinical trials. ${ }^{9}$ Having a better understanding of such outcomes may help oncologists and payers to make more informed decisions regarding treatment choices and reimbursement of these medicines. ${ }^{10-12}$

The primary objective of the current study was to estimate medication persistence and compliance (adherence) among patients with advanced RCC receiving pazopanib as first-line therapy or after previous treatment with $\geq 1$ other therapies outside the clinical trial setting. Secondary objectives were to describe patient characteristics and other treatment and utilization patterns by line of therapy, as well as examine predictors of persistence and compliance among the overall population.

This study used a third-party de-identified database provided by Truven Health MarketScan Research Databases, which contain individual, de-identified health care claims information from employers, health plans, hospitals, Medicare, and Medicaid programs. Used primarily for research, these databases are fully Health Insurance Portability and Accountability Act (HIPAA) compliant. Therefore, this study is exempt from international institutional review board approval.

\section{Methods}

\section{Data Source}

A retrospective, cohort observational study was conducted, utilizing claims data from the Truven Health MarketScan Commercial Claims and Encounters Database (includes employee and dependents' inpatient, outpatient, and outpatient prescription drug experience) and Truven Health MarketScan Medicare Supplemental and Coordination of Benefits Database (includes health care experience of individuals with employerpaid Medicare supplemental insurance). ${ }^{13}$ For this study, the claims covered dates of service between October 1, 2007, and March 31, 2012.

Information available from both databases was used to provide information about patient baseline characteristics, including age; gender (male or female); type of coverage (commercial or Medicare); type of insurance plan (comprehensive, preferred provider organization [PPO], point of service [POS], or health maintenance organization [HMO]); and dates of enrollment in the plan. Data available for each outpatient pharmacy claim (prescription filled) included the drug dispensed in National Drug Code (NDC) format (see Appendix A, available in online article), dispensing date, and quantity and number of therapy-days dispensed. Data available for each medical claim included dates of service and diagnosis codes in International Classification of Diseases, Ninth Revision, Clinical Modification (ICD-9-CM) format for disease history, risk factors, and comorbidities (see Appendix B, available in online article). Medical claims also included surgical and medical procedure codes in Current Procedural Terminology, Version 4 (CPT-4) and Health Care Financing Common Procedural Coding System formats (Appendix B, available in online article).

\section{Study Sample Selection}

Eligible patients required evidence of receipt of pazopanib by at least 1 claim for pazopanib (NDC: 0173-0804-09) between October 1, 2009, and September 30, 2011. The date of the first pharmacy claim for pazopanib during this period was set as the index date. Evidence of advanced RCC was also required, demonstrated by at least 2 claims with a primary diagnosis for RCC (ICD-9-CM: 189.0, 189.1) at least 30 days apart and within 2 years prior to the index date and at least 1 claim with a diagnosis of metastatic disease (ICD-9-CM: 196.xx-199.xx). At least 1 primary RCC diagnosis code must have appeared prior to or on the same date as the claim with the metastatic RCC diagnosis. Patients who were continuously enrolled in the health plan for at least 60 days prior to the index date and for at least 180 days after the index date and who were aged at least 18 years on the index date were selected for further analysis. The study used a 1-year pre-index period to define patient baseline characteristics. The postperiod was defined as 180 days post-index date and was used to assess all study measures listed in Table 1.

Two patient cohorts were defined: (1) treatment-naive pazopanib users who had no evidence of therapies used to treat advanced RCC between their metastatic diagnosis date and the index date (first-line cohort), and (2) pazopanib users with a history of treatment with $\geq 1$ other therapies prior to initiating pazopanib (previously treated cohort). 


\section{Persistence and Compliance with Pazopanib in Patients with Advanced \\ Renal Cell Carcinoma Within a U.S. Administrative Claims Database}

\section{TABLE 1 Definitions of Study Measures}

\begin{tabular}{|c|c|}
\hline Persistence & e duration of time (i.e., number of days) from initiation to discontinuation of therapy. ${ }^{7}$ \\
\hline $\begin{array}{l}\text { Estimated level of persis- } \\
\text { tence with therapy (ELPT) }\end{array}$ & $\begin{array}{l}\text { The percentage of individuals remaining on therapy at 30,60, and } 90 \text { days until the run-out date prior to a } 30 \text {-day gap in } \\
\text { therapy. }{ }^{8}\end{array}$ \\
\hline $\begin{array}{l}\text { Time to discontinuation } \\
\text { of therapy }\end{array}$ & $\begin{array}{l}\text { A sufficiently large gap in therapy ( } 30 \text { days) from the time of treatment initiation. The date of discontinuation was defined as the } \\
\text { date when the days' supply of the last prescription filled ran out prior to the gap in therapy, plus } 15 \text { days. }{ }^{8}\end{array}$ \\
\hline Covered days & The number of days during the treatment period for which the patient had a supply of pazopanib on hand. \\
\hline Days' supply & The number of days supplied on the most recent prior pazopanib claim minus the number of days elapsed since that claim. \\
\hline $\begin{array}{l}\text { Proportion of days } \\
\text { covered (PDC) }\end{array}$ & $\begin{array}{l}\text { The ratio of pazopanib covered days (drug on hand) to the duration of the pazopanib treatment period (number of days). }{ }^{8} \text { PDC }=\text { the } \\
\text { ratio of (total days drug available minus days' supply of last prescription) to (last prescription date minus first prescription date). }\end{array}$ \\
\hline Compliance (adherence) & $\begin{array}{l}\text { The extent to which a patient acts in accordance with the prescribed interval and dose of a dosing regimen, }{ }^{7} \text { measured by } \\
\text { medication possession ratio. }\end{array}$ \\
\hline $\begin{array}{l}\text { Medication possession } \\
\text { ratio (MPR) }\end{array}$ & $\begin{array}{l}\text { The proportion of time over the course of a patient's treatment that he/she theoretically was in possession of medication. }{ }^{8} \\
\text { MPR = the ratio of (the number of total days' supply of pazopanib [not including the last refill]) to (the duration of pazopanib } \\
\text { therapy [number of days between first and last fill]). The maximum MPR was } 1.0 \text {; that is, patients who are perfectly compliant } \\
\text { will have MPRs of 1.0, whereas those who are less than fully compliant will have MPRs }<1.0 \text {. }\end{array}$ \\
\hline $\begin{array}{l}\text { Time to initiation of } \\
\text { therapy }\end{array}$ & The number of days from metastatic diagnosis to the first pazopanib claim (index date). \\
\hline $\begin{array}{l}\text { Time to switching to } \\
\text { another therapy }\end{array}$ & $\begin{array}{l}\text { Among patients who discontinued pazopanib, the number of days to initiation of the new drug. Patients were followed until } \\
\text { switching, end of eligibility, or end of study, whichever came first. }\end{array}$ \\
\hline $\begin{array}{l}\text { Average daily dose (with- } \\
\text { out any dose interruptions) }\end{array}$ & The quantity of medication supplied multiplied by drug strength/days' supply. \\
\hline Initial daily dosage (IDD) & $\begin{array}{l}\text { The product of the milligram }(\mathrm{mg}) \text { per tablet for pazopanib }(200 \mathrm{mg}) \text { and the prescribed number of pills per days for the index } \\
\text { claim. The prescribed number of pills per day was the ratio of the quantity supplied to the days supplied on the index claim. }\end{array}$ \\
\hline di & $\begin{array}{l}\text { the final pazopanib fill prior to discontinuation of pazopanib, switching, end of eligibility, or end of } \\
\text { rst. }\end{array}$ \\
\hline
\end{tabular}

\section{Study Measures}

There were 12 measures studied, which are defined in Table 1. Persistence was measured using estimated level of persistence with therapy (ELPT), time to discontinuation, and proportion of days covered (PDC). Compliance was measured using medication possession ratio (MPR). ${ }^{14,15}$ Other treatment and utilization patterns measured included time to initiation of therapy, time to switching to another therapy, average daily dose, initial daily dose (IDD), and ending dose.

Random forests methodology (see Appendix C, available in online article) was used to select predictor variables for both persistence (PDC) and compliance (MPR) models. ${ }^{16,17}$ The predictors included in the models were age, Charlson Comorbidity Index (CCI), plan type, treatment-naïve or first-line, gender (sex), IDD, and commercial versus Medicare population.

\section{Statistical Analysis}

All statistical analyses were performed using SAS version 9.2 (SAS Institute Inc., Cary, NC). The random forest models were performed using R 2.15.1 (http://www.r-project.org/). All treatment and utilization variables were analyzed descriptively. Means, medians, standard deviations (SDs), and ranges were provided for continuous variables. Numbers and percentages were provided for categorical variables. PDC and MPR were multiplied by 100 to yield a percentage, set as a dichotomous variable, and categorized as either low or high based on $<80 \%$ versus $\geq 80 \%$, respectively. Bivariate comparisons between first-line and previously treated patient results were conducted. Appropriate tests (e.g., t-test, Mann Whitney-U test, chi-square test) were used based on the distribution of the measure. The a priori alpha level for relevant analyses was set at 0.05 , and all statistical tests were two-tailed, unless otherwise specified. Time-to-event endpoints were analyzed using Kaplan-Meier methods.

\section{Results}

\section{Patient Characteristics}

A total of 143 patients (62 first-line and 81 previously treated) met all inclusion criteria (Figure 1). The greatest source of attrition was the requirement for continuous eligibility 60 days pre-index and 6 months post-index (182 patients excluded).

The mean age of all pazopanib users was 62.9 years; $71.3 \%$ of users were male; and 55.2\% had a PPO-type insurance plan (Table 2). The year of advanced RCC diagnosis was about evenly distributed from 2008 to 2010, with patients having an average of about 1 year since initial RCC diagnosis. Most patients had CCI scores $\geq 7$ (90.9\%), and $60.8 \%$ had hypertension. Among the previously treated cohort $(n=81), 40$ were previously treated with sunitinib, 32 with everolimus, 19 each with sorafenib and temsirolimus, 8 with bevacizumab, and 4 with interferons. These were not mutually exclusive groups, and patients may have received $>1$ of these therapies prior to initiating pazopanib. 


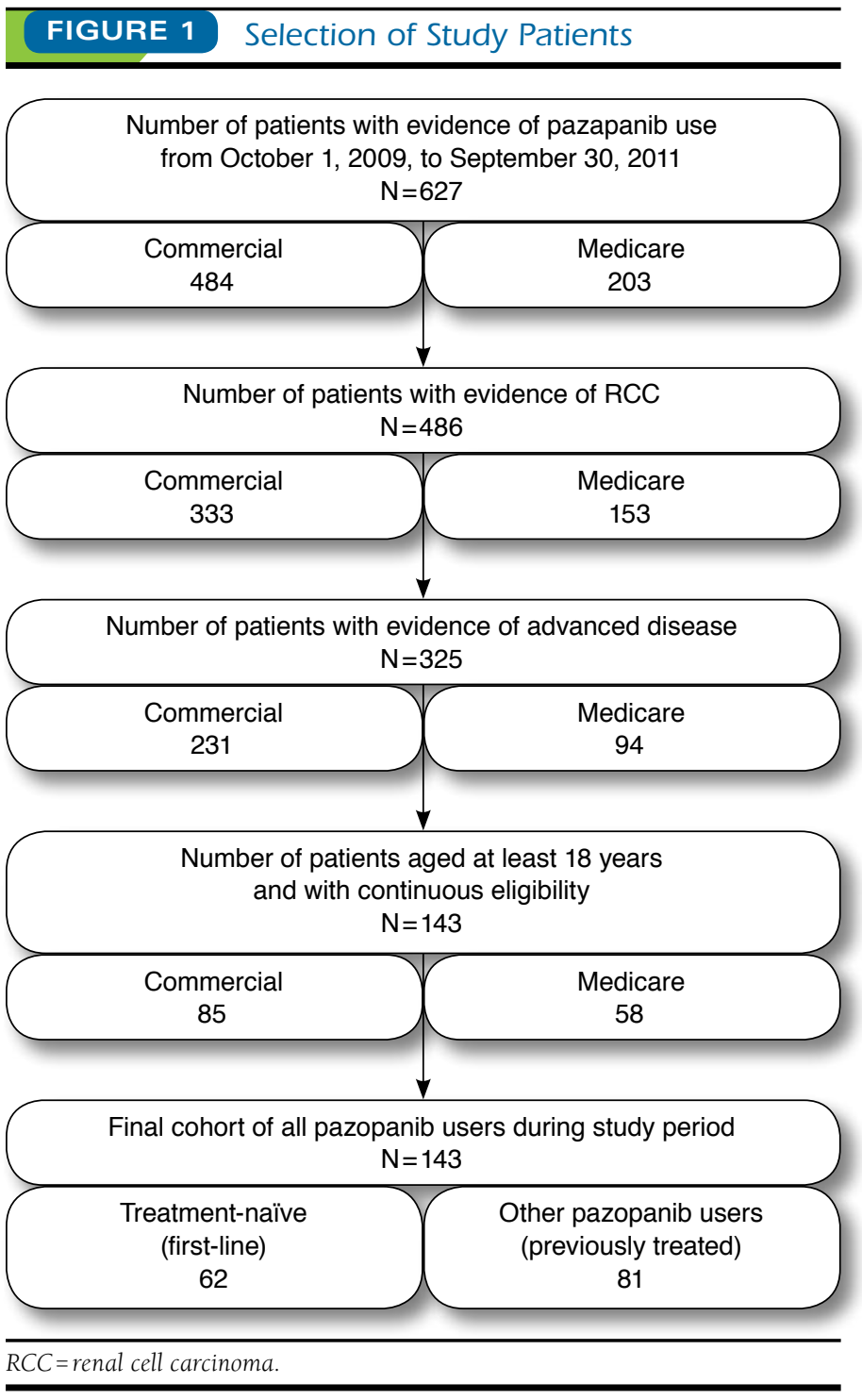

\section{Persistence and Compliance}

Continuous pazopanib therapy for up to 90 days was observed in more than $50 \%$ of patients in both cohorts (Table 3). ELPT at 30,60, and 90 days was similar between the first-line and previously treated cohorts. Two patients (1 from each cohort) discontinued pazopanib therapy within the first 30 days. The patient-persistence curve (Figure 2) indicates that at 6 months (180 days), 33\% of first-line patients and 38\% of previously treated patients were still persistent with pazopanib therapy. The mean and median time to pazopanib discontinuation, or average duration of pazopanib therapy, was also similar in the first-line versus previously treated cohorts (Table 3). A significantly greater number of patients in the previously treated cohort had high persistence (PDC $\geq 80 \%$ ) compared with

\section{TABLE 2 Patient Baseline Characteristics}

\begin{tabular}{|c|c|c|c|c|}
\hline Baseline Characteristics & $\begin{array}{c}\text { Total } \\
(\mathrm{N}=143)\end{array}$ & $\begin{array}{l}\text { First-Line } \\
(n=62)\end{array}$ & $\begin{array}{c}\text { Previously } \\
\text { Treated } \\
(\mathrm{n}=81)\end{array}$ & $\begin{array}{c}P \\
\text { Value }^{\mathrm{a}}\end{array}$ \\
\hline Age, mean [SD] & 62.9 [10.3] & $65.6[10.1]$ & 60.9 [10.0] & 0.007 \\
\hline Minimum-maximum & $38-89$ & $49-89$ & $38-82$ & \\
\hline \multicolumn{4}{|l|}{ Gender, n (\%) } & 0.159 \\
\hline Male & $102(71.3)$ & $48(77.4)$ & $54(66.7)$ & \\
\hline Female & $41(28.7)$ & $14(22.6)$ & $27(33.3)$ & \\
\hline \multicolumn{4}{|l|}{ Plan type, n (\%) } & 0.015 \\
\hline Comprehensive & $25(17.5)$ & $13(21.0)$ & $12(14.8)$ & \\
\hline $\mathrm{HMO}$ & $19(13.3)$ & $6 \quad(9.7)$ & $13(16.1)$ & \\
\hline POS (including capitation) & $9(6.3)$ & $8(12.9)$ & $1 \quad(1.2)$ & \\
\hline $\mathrm{PPO}$ & $79(55.2)$ & $34(54.8)$ & $45(55.5)$ & \\
\hline Otherb & $9 \quad(6.3)$ & $1 \quad(1.6)$ & $8 \quad(9.9)$ & \\
\hline Missing & $2(1.4)$ & $0(0.0)$ & $2(2.5)$ & \\
\hline \multicolumn{4}{|l|}{ Population, n (\%) } & 0.005 \\
\hline Commercial & $85(59.4)$ & $27(43.6)$ & $58(71.6)$ & \\
\hline Medicare & $58(40.6)$ & $35(56.4)$ & $23(28.4)$ & \\
\hline \multicolumn{4}{|l|}{ Year of diagnosis, $\mathbf{n}(\%)$} & 0.046 \\
\hline 2007 & $2 \quad(1.4)$ & $1 \quad(1.6)$ & $1 \quad(1.2)$ & \\
\hline 2008 & $47(32.8)$ & $15(24.2)$ & $32(39.5)$ & \\
\hline 2009 & $42(29.4)$ & $16(25.8)$ & $26(32.1)$ & \\
\hline 2010 & $49(34.3)$ & $27(43.6)$ & $22(27.2)$ & \\
\hline 2011 & $3(2.1)$ & $3(4.8)$ & $0 \quad(0.0)$ & \\
\hline $\begin{array}{l}\text { Years since first RCC } \\
\text { diagnosis, mean [SD] }\end{array}$ & $1.1[0.6]$ & $0.9[0.7]$ & $1.3[0.6]$ & 0.108 \\
\hline Surgery for RCC, n (\%) & $21(14.7)$ & $13(20.9)$ & $8 \quad(9.9)$ & 0.063 \\
\hline Nephrectomy, n (\%) & $20(13.9)$ & $12(19.4)$ & $8 \quad(9.9)$ & 0.061 \\
\hline CCI, mean [SD] & $10.0[3.2]$ & $9.5[3.6]$ & $10.4[2.7]$ & 0.109 \\
\hline \multicolumn{4}{|l|}{ CCI, n (\%) } & 0.083 \\
\hline $0-6$ & $13 \quad(9.1)$ & $10(16.1)$ & $3(3.7)$ & \\
\hline $7-9$ & $44(30.8)$ & $18(29.0)$ & $26(32.1)$ & \\
\hline $10-11$ & $42(29.3)$ & $16(25.8)$ & $26(32.1)$ & \\
\hline $12+$ & $44(30.8)$ & $18(29.0)$ & $26(32.1)$ & \\
\hline \multicolumn{5}{|c|}{ Risk factors and comorbidities, n (\%) } \\
\hline Dialysis & $3(2.1)$ & $0 \quad(0.0)$ & $3(3.7)$ & 0.125 \\
\hline Hypertension & $87(60.8)$ & $36(58.1)$ & $51(62.9)$ & 0.552 \\
\hline Kidney abnormalities & $1 \quad(0.7)$ & $0 \quad(0.0)$ & $1 \quad(1.2)$ & 0.380 \\
\hline PKD & $4(2.8)$ & $3(4.8)$ & $1 \quad(1.2)$ & 0.195 \\
\hline VHL disease & \begin{tabular}{ll|}
0 & $(0.0)$ \\
\end{tabular} & $0 \quad(0.0)$ & $\begin{array}{ll}0 & (0.0) \\
\end{array}$ & $\mathrm{NA}$ \\
\hline \multicolumn{5}{|c|}{$\begin{array}{l}\text { a t-test was used to compare means; a chi-square test was used to compare pro- } \\
\text { portions; Fisher's exact test was used to compare proportions for cell sizes < } 5 \text {. } \\
\text { b"Other" plan type included basic/major medical, exclusive provider organization, } \\
\text { noncapitated point-of-service, consumer-driven health plan, and high deductible } \\
\text { health plan. } \\
C C I=\text { Charlson Comorbidity Index; HMO=health maintenance organization; } \\
\mathrm{N} / \mathrm{A}=\text { not applicable; } P K D=\text { polycystic kidney disease; } P O S=\text { point of service; } \\
P P O=\text { preferred provider organization; } R C C=\text { renal cell carcinoma; } S D=\text { standard } \\
\text { deviation; } V H L=\text { von Hippel Lindau disease. }\end{array}$} \\
\hline
\end{tabular}

those in the first-line cohort $(80.3 \%$ vs. $64.5 \%$, respectively; $P=0.034)$.

Only 126 patients were assessed for MPR because 17 patients did not have at least 2 pazopanib claims within the database needed for the MPR calculation (Table 3). First-line 


\section{TABLE 3}

Persistence, Compliance, and

Treatment/Use Patterns with

Pazopanib Therapy

\begin{tabular}{l|c|c|c}
\hline Study Measures & $\begin{array}{c}\text { First-Line } \\
(\mathrm{n}=62)\end{array}$ & $\begin{array}{c}\text { Previously } \\
\text { Treated } \\
(\mathrm{n}=81)\end{array}$ & $\begin{array}{c}P \\
\text { Value }^{\mathrm{a}}\end{array}$ \\
\hline
\end{tabular}

ELPT at time point, $\mathrm{n}(\%)$

\begin{tabular}{|c|c|c|c|}
\hline 30 days & $61(98.39)$ & $80(98.77)$ & 0.848 \\
\hline 60 days & $44(70.97)$ & $61(75.31)$ & 0.360 \\
\hline 90 days & $35(56.45)$ & $47(58.02)$ & 0.850 \\
\hline \multicolumn{4}{|c|}{ Number of days to discontinuation/duration of therapy } \\
\hline Mean [SD] & $\begin{array}{l}112.2 \\
{[62.8]}\end{array}$ & $\begin{array}{l}118.7 \\
{[61.4]}\end{array}$ & 0.533 \\
\hline Median (range) & $\begin{array}{c}111.5 \\
(0-180) \\
\end{array}$ & $\begin{array}{c}123.0 \\
(28-180) \\
\end{array}$ & \\
\hline
\end{tabular}

PDC

\begin{tabular}{l|c|c|c}
\hline Mean [SD], days & $84.7[16.7]$ & $87.8[13.5]$ & 0.222 \\
\hline High persistence, PDC $\geq 80 \%, \mathrm{n}(\%)$ & $40(64.5)$ & $65(80.3)$ & 0.034 \\
\hline MPR & $\mathbf{n}=\mathbf{5 4}$ & $\mathbf{n}=\mathbf{7 2}$ & \\
\hline Mean [SD] & $85.2[16.9]$ & $90.1[13.9]$ & 0.069 \\
\hline High compliance, MPR $\geq 80 \%, \mathrm{n}(\%)$ & $36(66.7)$ & $60(83.3)$ & 0.029 \\
\hline
\end{tabular}

Days' supply of initial pazopanib therapy, $\mathbf{n}(\%)$

\begin{tabular}{|c|c|c|c|}
\hline 7 & $0 \quad(0.0)$ & $1 \quad(1.2)$ & \multirow[t]{5}{*}{0.153} \\
\hline 21 & $0 \quad(0.0)$ & $1 \quad(1.2)$ & \\
\hline 28 & $1 \quad(1.6)$ & $3 \quad(3.7)$ & \\
\hline 30 & $57(91.9)$ & $73(90.2)$ & \\
\hline 90 & $4 \quad(6.5)$ & $3 \quad(3.7)$ & \\
\hline $\begin{array}{l}\text { Days' supply of pazopanib therapy } \\
\text { over } 180 \text { days, mean [SD] (range) }\end{array}$ & $\begin{array}{c}125.9[59.8] \\
(30-210)\end{array}$ & $\begin{array}{c}131.1[67.3] \\
(28-300)\end{array}$ & 0.487 \\
\hline $\begin{array}{l}\text { Time to initiation (i.e., number of } \\
\text { days) of pazopanib therapy, mean } \\
\text { [SD] (range) }\end{array}$ & $\begin{array}{l}104.7[199.3] \\
\quad(0-650)\end{array}$ & $\begin{array}{l}360.9[187.0] \\
\quad(64-720)\end{array}$ & 0.001 \\
\hline $\begin{array}{l}\text { Time to switching (i.e., number of } \\
\text { days) to another therapy, mean [SD] } \\
\text { (range) }\end{array}$ & $\begin{array}{c}\mathbf{n}=\mathbf{1 7} \\
94.7[41.4] \\
(6-176)\end{array}$ & $\begin{array}{c}\mathbf{n}=29 \\
87.8[49.6] \\
(0-175)\end{array}$ & 0.146 \\
\hline \multicolumn{4}{|l|}{ Pazopanib dosing, mean [SD] } \\
\hline Average daily dose, $\mathrm{mg}$ & $763[122]$ & $703[220]$ & 0.055 \\
\hline Initial daily dose, $\mathrm{mg}$ & $761[130]$ & $686[240]$ & 0.028 \\
\hline Ending dose, $\mathrm{mg}$ & 768 [109] & 686 [235] & 0.013 \\
\hline
\end{tabular}

${ }^{a} \mathrm{~A}$ t-test was used to compare means; a chi-square test was used to compare proportions; Fisher's exact test was used to compare proportions for cell sizes $<5$.

$E L P T=$ estimated level of persistence with therapy; $m g=$ milligram; $M P R=$ medication possession ratio; $P D C=$ proportion of days covered; $S D=$ standard deviation.

and previously treated patients had similar compliance. High compliance (MPR $\geq 80 \%$ ) was also significantly greater in the previously treated cohort than in the first-line cohort $(83.3 \%$ vs. $66.7 \%$, respectively; $P=0.029$ ).

\section{Treatment and Utilization Patterns}

On average ( \pm SD), there was a 104.7 ( \pm 199.3)-day gap between the time from metastatic diagnosis to start of pazopanib therapy in patients from the first-line cohort versus a 360.9 $( \pm 187.0)$-day gap for patients in the previously treated cohort $(P=0.001)$. Almost all patients in both cohorts $(91.9 \%$ of firstline and $90.2 \%$ of previously treated patients) had at least a

\section{FIGURE 2 ELPT Curve for Pazopanib at 30,60 , and 90 Days $(N=143$ )}

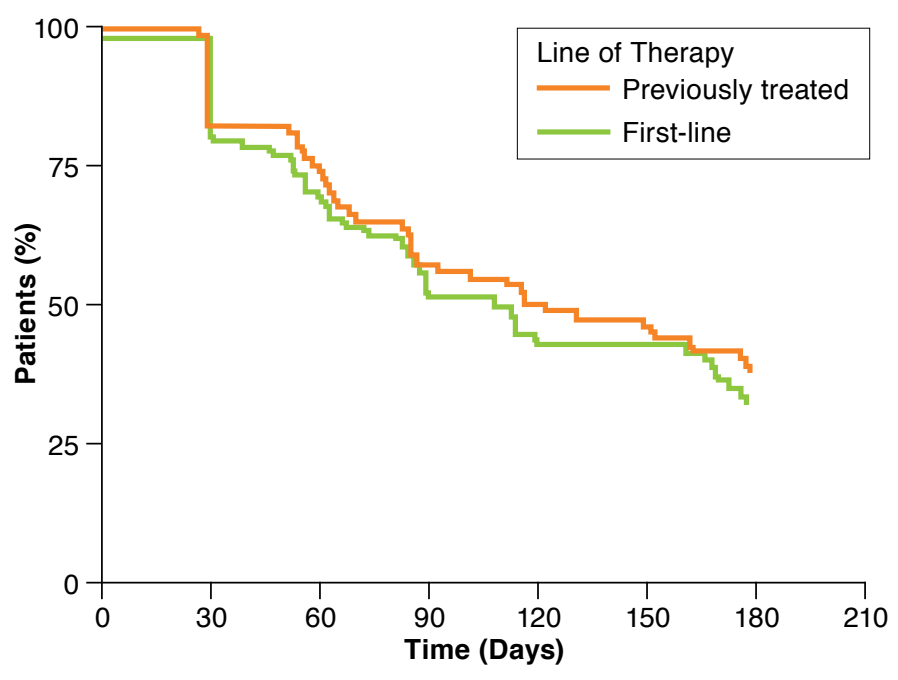

ELPT=estimated level of persistence with therapy.

30-day supply of therapy, and $6.5 \%$ of first-line and $3.7 \%$ of previously treated patients had a 90 -day supply (Table 3 ). The average ( \pm SD) days' supply of pazopanib therapy over 180 days was $125.9( \pm 59.8)$ in the first-line cohort and 131.1 $( \pm 67.3)$ in the previously treated cohort. Forty-six patients switched to another therapy: 17 patients in the first-line cohort and 29 patients in the previously treated cohort; the mean $( \pm S D)$ time to switching therapy from each cohort was $94.7( \pm 41.4)$ days and $87.8( \pm 49.6)$ days $(P=0.146)$, respectively.

The average $( \pm$ SD) daily dose of pazopanib was $763( \pm 122)$ $\mathrm{mg}$ in the first-line cohort and $703( \pm 220) \mathrm{mg}$ in the previously treated cohort. Additionally, the maximum average daily dose during the entire pazopanib use period was $800 \mathrm{mg}$ in both cohorts. The average $( \pm S D)$ initial daily dose of pazopanib was $761( \pm 130) \mathrm{mg}$ in the first-line cohort and $686( \pm 240) \mathrm{mg}$ in the previously treated cohort; this difference was statistically significant $(P=0.028$; Table 3$)$. The mean $( \pm S D)$ ending dose of pazopanib was $768( \pm 109) \mathrm{mg}$ in the first-line cohort and $686( \pm 235) \mathrm{mg}$ in the previously treated cohort, representing a statistically significant difference $(P=0.013)$.

\section{Factors Associated with Persistence and Compliance}

Figure 3 shows the random forest plots with persistence (PDC; Figure 3A-C) and compliance (MPR; Figure 3D-F) as outcomes in the models. Figure $3 \mathrm{~A}$ and $3 \mathrm{D}$ demonstrate how age and CCI most strongly correlated with each outcome (Gini $>8$ ). The correlations also demonstrate that younger age (Figure 3B and 3E) and higher CCI (Figure 3C and 3F) each predicted higher persistence and higher compliance. 


\section{A. Most Important Variables for PDC $\geq 80 \%$}

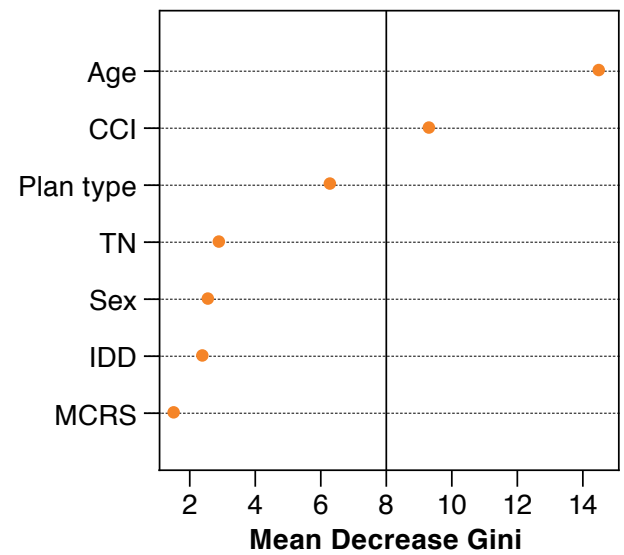

D. Most Important Variables for MPR $\geq 80 \%$

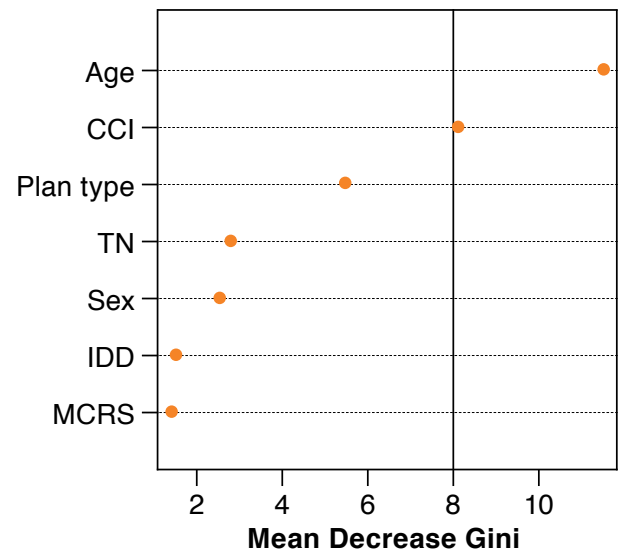

B. PDC $\geq 80 \%$ and Age

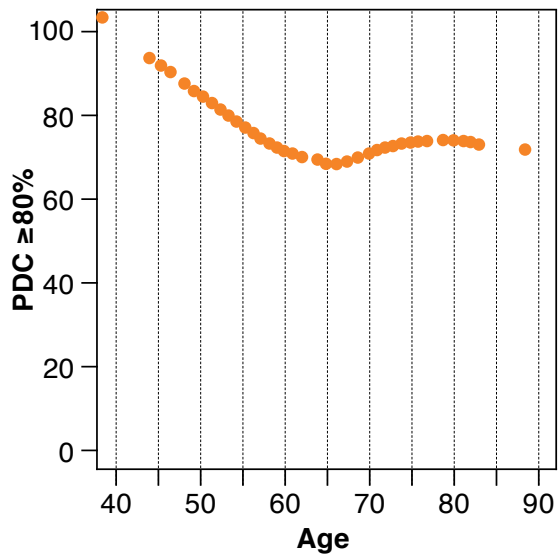

E. MPR $\geq 80 \%$ and Age

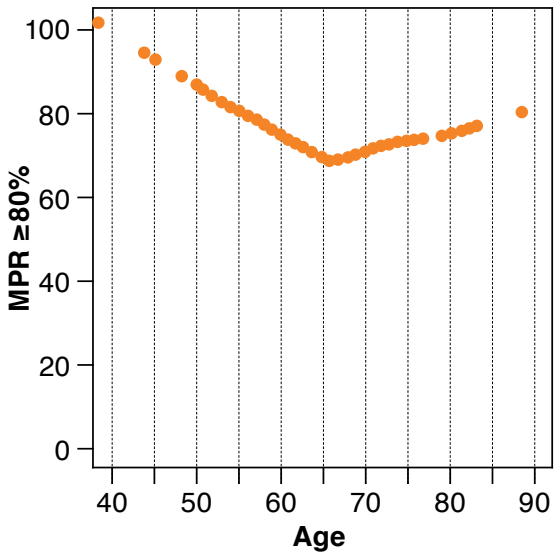

C. $\mathrm{PDC} \geq 80 \%$ and $\mathrm{CCl}$

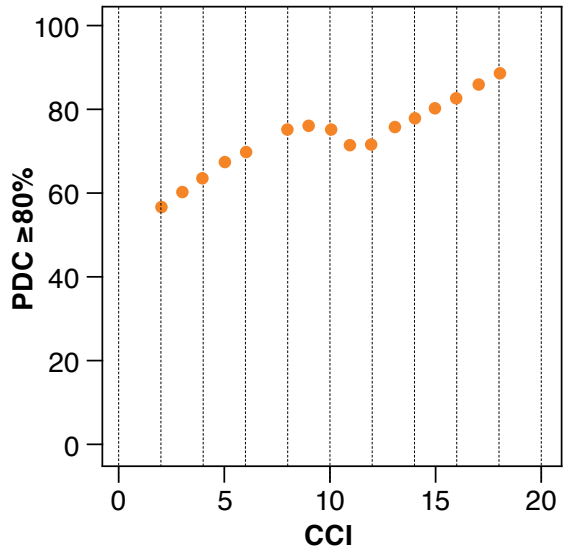

F. MPR $\geq 80 \%$ and $\mathrm{CCl}$

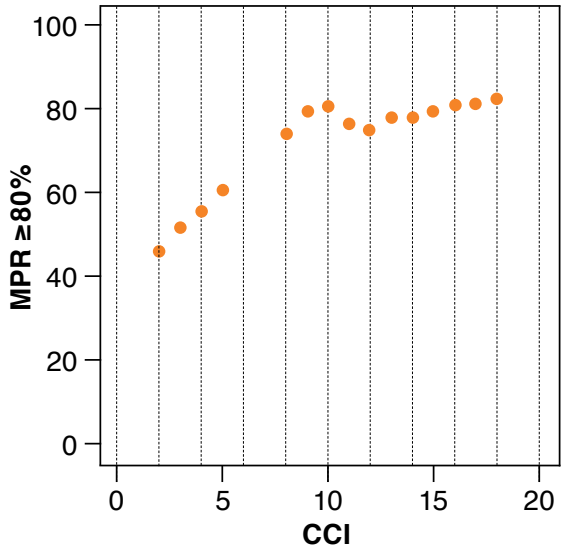

CCI = Charlson Comorbidity Index; IDD = initial daily dose; Gini = index that measures for statistical dispersion; MCRS= commercial versus Medicare population; $M P R=$ medication possession ratio; $P D C=$ proportion of days covered; Sex=gender; $T N=$ treatment-naïvelfirst-line.

\section{Discussion}

Evidence suggests that routinely assessing adherence and implementing adherence programs can lead to improved health status. ${ }^{18}$ While some studies now include adherence assessments, the rates reported in clinical trials may be higher than those observed outside of trials due to biases in assessment of adherence, such as response bias and recall bias in self-reporting, as well as careful patient selection during recruitment and the intense attention paid to those enrolled. The mechanism of action of many oral cancer therapies is cytostatic in nature, such that they are optimally effective when given chronically; therefore, daily oral therapy is required to control the disease. ${ }^{19}$ Nonadherence can contribute greatly to the variability observed in a drug's therapeutic effect and may also increase costs due to increased physician visits, unnecessary diagnostic testing, higher hospitalization rates, longer hospital stays, and changes in dose or regimen. ${ }^{18}$

Few studies on persistence and compliance with oral therapies have been conducted in patients with RCC, despite that many therapies to treat this disease are orally available agents. A prospective, multicenter, observational study (Investigating Patient Satisfaction with Oral Anti-cancer Treatment) of patients with advanced RCC is ongoing in Belgium. Preliminary results from this trial suggest high adherence in this patient population. ${ }^{20}$ Previous U.S. studies retrospectively assessing treatment patterns of targeted agents used as first-line therapy for RCC have mostly reported results of patients receiving sorafenib (approved in 2005) and sunitinib (approved in 2006), with 
small sample sizes limiting assessments of other agents, including pazopanib. ${ }^{21-24} \mathrm{~A}$ retrospective database study of dosing patterns of first-line sunitinib, dosed once daily on a 4-weeks-on, 2-weeks-off dosing schedule, showed that patients commonly underwent sunitinib dose reductions within the first 3 treatment cycles due to toxicity and discontinued therapy within the first 5 cycles due to progressive disease. ${ }^{25}$ Combined, the findings from these studies suggest that a high percentage of patients in routine clinical settings could discontinue treatment with TKIs in $<6$ months. ${ }^{21-24}$ These findings are also in contrast with the duration of therapy reported in phase 111 trials of sorafenib and sunitinib. ${ }^{26,27}$ These differences may indicate that patient selection or adverse event (AE) management in clinical trials may differ from that in routine practice. Feinberg et al. (2012) assessed treatment patterns from medical records and found that most discontinuations from sunitinib and sorafenib were attributed to disease progression (34\% vs. 37\%) and AEs (24\% vs. $31 \%)^{21}$

Overall duration of pazopanib therapy observed in this observational study was lower than that observed in clinical trials yet consistent between the first-line and previously treated cohorts. Median treatment duration for patients receiving pazopanib in the pivotal and COMPARZ clinical trials was $7.4^{6}$ and 8.0 months, ${ }^{5}$ respectively, whereas the median duration of therapy in this study was almost 4 months (111.5 days in the first-line cohort and 123.0 days in the previously treated cohort). However, continuous pazopanib therapy for up to 90 days was observed in $>50 \%$ of patients in both the first-line and previously treated cohorts. In addition, high persistence (PDC $\geq 80 \%$ ) and high compliance (MPR $\geq 80 \%$ ) were observed in both cohorts. The average daily pazopanib dose was $>700$ $\mathrm{mg}$ in both cohorts, with a maximum dose of $800 \mathrm{mg}$, implying that patients were administered pazopanib according to the recommended dose. ${ }^{7}$ However, any dose changes were not assessed in our study due to the short follow-up period. Among various factors, younger age and higher comorbidity both demonstrated the strongest correlations with higher persistence and compliance. Differences in patient population, sample size, methodology, and practice settings among these previous studies and the current study preclude direct comparisons of the results. However, these data indicate the need to better understand the differences in study measures between clinical trial results and those in routine clinical practice. Patient selection, AE management, cost to the patient, and patient preferences are potential areas that should be assessed.

Results of the current study provide implications for future research. While the mean persistence and compliance observed with pazopanib in this study are relatively high, approximately $35 \%$ of patients in the first-line cohort and $20 \%$ in the previously treated cohort had PDC and MPR $<80 \%$.
Further research is needed to better understand the reasons for discontinuation of drug use and nonadherence in these subgroups. The time to initiation of pazopanib treatment from the diagnosis of metastatic disease ranged from 3 months for first-line users to 1 year for patients treated with another firstline therapy prior to pazopanib. Additionally, a small proportion of patients were on therapy for approximately 3 months prior to discontinuation and switching to another therapy. It would be useful to explore the reasons for prescribing patterns and discontinuation and whether they are associated with pazopanib-related AEs.

\section{Limitations}

This retrospective analysis used health insurance claims data and is limited to the variables that are included within that data. The data are also subject to coding errors and incomplete claims history and clinical information. Our estimates of persistence and compliance do not account for the possibility that patients acquired prescription medications from pharmacies not included in the database or participated in clinical trials. We also do not confirm actual ingestion of the medication by patients. Post-index factors such as treatment response and AEs were not examined as predictors of persistence and compliance. Finally, although the database is geographically diverse, it is based on a small convenience sample that is not representative of the U.S. population; therefore, the findings may not be generalizable to all populations.

\section{Conclusions}

More than one-half of patients with advanced RCC in this study were on pazopanib for almost 4 months and were persistent and compliant. Younger age and higher comorbidity index were the strongest predictors of both greater persistence and compliance with pazopanib therapy. Further studies with larger cohorts and longer follow-up are needed to validate our findings.

\section{Authors}

MICHELLE D. HACKSHAW, BScPharm, MSHS, PhD, is Director, U.S. Health Outcomes Oncology, and LESLEY-ANN N. MILLER, MS, PhD, is Specialty Health Outcomes Liaison, U.S. Health Outcomes, GlaxoSmithKline, Philadelphia, Pennsylvania. SAURABH P. NAGAR, BPharm, MS, is Data Analyst, U.S. Payer Evidence Group, and DANIEL C. PARKS, MS, PhD, is Medical Analytics Manager, U.S. Payer Evidence Group, GlaxoSmithKline, Research Triangle Park, North Carolina.

AUTHOR CORRESPONDENCE: Michelle D. Hackshaw, BScPharm, MSHS, PhD, 5 Crescent Dr., Philadelphia, PA 19112. Tel.: 215.751.6155; Fax: 215.751-7572; E-mail: michelle.d.hackshaw@gsk.com. 


\section{Persistence and Compliance with Pazopanib in Patients with Advanced Renal Cell Carcinoma Within a U.S. Administrative Claims Database}

\section{DISCLOSURES}

This study was sponsored by GlaxoSmithKline (GSK). Hackshaw, Nagar, Parks, and Miller are employees of, and hold stock in, GSK.

Study concept and design were contributed by Hackshaw, Nagar, Parks, and Miller. Data analysis was conducted by Nagar and Parks. Data interpretation was done by Hackshaw, Nagar, Parks, and Miller. Hackshaw, Nagar, Parks, and Miller wrote and revised the manuscript.

\section{ACKNOWLEDGMENTS}

The authors would like to thank Debasis Chakrabarti, MD, PhD, for his contribution to the study design and critical review of early drafts of this manuscript. He was the Medical Director for Votrient, U.S. Medical Affairs, GlaxoSmithKline (GSK), at the time of this study. Editorial assistance was provided by Vanessa Marrero, PhD, and Nancy Price, PhD, of AOI Communications, L.P., and was funded by GSK.

\section{REFERENCES}

1. American Cancer Society. Cancer facts and figures 2013. Atlanta: American Cancer Society; 2013. Available at: http://www.cancer.org/acs/ groups/content/@epidemiologysurveilance/documents/document/acspc036845.pdf. Accessed March 18, 2014.

2. Siegel R, Naishadham D, Jemal A. Cancer statistics, 2013. CA Cancer J Clin. 2013;63(1):11-30. Available at: http://onlinelibrary.wiley.com/ doi/10.3322/caac.21166/abstract. Accessed March 18, 2014

3. Motzer RJ, Russo P. Systemic therapy for renal cell carcinoma. J Urol. 2000;163(2):408-17.

4. National Comprehensive Cancer Network. Clinical Practice Guidelines in Oncology. Kidney Cancer, Version 2.2014. Available at: https://subscriptions nccn.org/gl_login.aspx?ReturnURL=http://www.nccn.org/professionals/physician_gls/pdf/kidney.pdf. Accessed March 28, 2014.

5. Motzer RJ, Hutson TE, Cella D, et al. Pazopanib versus sunitinib in metastatic renal-cell carcinoma. N Engl J Med. 2013;369(8):722-31.

6. Sternberg CN, Davis ID, Mardiak J, et al. Pazopanib in locally advanced or metastatic renal cell carcinoma: results of a randomized phase III trial. J Clin Oncol. 2010;28(6):1061-68. Available at: http://jco.ascopubs.org/content/28/6/1061.long. Accessed March 18, 2014.

7. Votrient (pazopanib) tablets. GlaxoSmithKline. Revised August 2013. Available at: http://us.gsk.com/products/assets/us_votrient.pdf. Accessed March 18, 2014.

8. Dunn R, Gochenauer G. The promise of oral anticancer agents: addressing compliance and affordability. Oncology Business Review. 2012;6(5). Available at: https://obroncology.com/obrgreen/article/The-Promise-of-OralAnticancer-Agents:-Addressing-Compliance-and-Affordability. Accessed March 18, 2014.

9. Hohneker J, Shah-Mehta S, Brandt PS. Perspectives on adherence and persistence with oral medications for cancer treatment. J Oncol Pract. 2011;7(1):65-67. Available at: http://jop.ascopubs.org/content/7/1/65.long. Accessed March 18, 2014

10. Verbrugghe M, Verhaeghe S, Lauwaert K, Beeckman D, Van Hecke A. Determinants and associated factors influencing medication adherence and persistence to oral anticancer drugs: a systematic review. Cancer Treat Rev. 2013;39(6):610-21

11. Gebbia V, Bellavia G, Ferrau F, Valerio MR. Adherence, compliance and persistence to oral antineoplastic therapy: a review focused on chemotherapeutic and biologic agents. Expert Opin Drug Saf. 2012;11(Suppl 1):S49-S59.

12. Foulon V, Schoffski P, Wolter P. Patient adherence to oral anticancer drugs: an emerging issue in modern oncology. Acta Clin Belg. 2011;66(2):85-96.

Available at: http://poj.peeters-leuven.be/content.php?url=article\&id=100292 3\&journal_code=ACB. Accessed March 18, 2014.
13. Hansen L, Chang S. Health research data for the real world: the MarketScan Databases. A White Paper. Truven Health Analytics. July 2012. Available at: http://truvenhealth.com/Portals/0/assets/2012_Truven_ MarketScan_white_paper.pdf. Accessed March 18, 2014

14. Cramer JA, Roy A, Burrell A, et al. Medication compliance and persistence: terminology and definitions. Value Health. 2008;11(1):44-47. Available at: http://onlinelibrary.wiley.com/doi/10.1111/j.1524-4733.2007.00213.x/full. Accessed March 18, 2014.

15. Peterson AM, Nau DP, Cramer JA, Benner J, Gwadry-Sridhar F, Nichol M. A checklist for medication compliance and persistence studies using retrospective databases. Value Health. 2007;10(1):3-12. Available at: http:// onlinelibrary.wiley.com/doi/10.1111/j.1524-4733.2006.00139.x/full. Accessed March 18, 2014.

16. Breiman L. Random forests. Machine Learning. 2001;45(1):5-32. Available at: http://link.springer.com/article/10.1023\%2FA\% 3A1010933404324. Accessed March 18, 2014.

17. Cleveland W, Devlin S. Locally weighted regression: an approach to regression analysis by local fitting. JASA. 1988;83(403):596-610. Available at: http://www.jstor.org/discover/10.2307/2289282?uid=3739552 \&uid=2\&ui $\mathrm{d}=4 \&$ uid $=3739256 \&$ sid $=21103787808423$. Accessed March 18, 2014.

18. Ruddy K, Mayer E, Partridge A. Patient adherence and persistence with oral anticancer treatment. CA Cancer J Clin. 2009;59(1):56-66. Available at: http://onlinelibrary.wiley.com/doi/10.3322/caac.20004/abstract;jsessionid=C E18A3CC2B255407EC03433A241B82F3.f03t04. Accessed March 18, 2014.

19. Weingart SN, Brown E, Bach PB, et al. NCCN Task Force Report: Oral chemotherapy. J Natl Compr Canc Netw. 2008;6(Suppl 3):S1-S14. Available at: http://www.nccn.org/JNCCN/PDF/JNSU3_combined_Oral_Chemo_2008. pdf. Accessed March 18, 2014.

20. Wolter P, Hendrickx T, Renard V, et al. Adherence to oral anticancer drugs (OAD) in patients (pts) with metastatic renal cancer (mRCC): First results of the prospective observational multicenter IPSOC study (Investigating Patient Satisfaction with Oral Anti-cancer Treatment). J Clin Oncol. 2012;30(Suppl):Abstract 4622. Available at: http://meetinglibrary. asco.org/content/96646-114. Accessed March 18, 2014.

21. Feinberg BA, Jolly P, Wang ST, et al. Safety and treatment patterns of angiogenesis inhibitors in patients with metastatic renal cell carcinoma: evidence from US community oncology clinics. Med Oncol. 2012;29(2):786-94.

22. Filson CP, Redman BG, Dunn RL, Miller DC. Initial patterns of care with oral targeted therapies for patients with renal cell carcinoma. Urology. 2011;77(4):825-30.

23. Hess G, Borker R, Fonseca E. Treatment patterns: targeted therapies indicated for first-line management of metastatic renal cell carcinoma in a real-world setting. Clin Genitourin Cancer. 2013;11(2):161-67.

24. Oh WK, McDermott D, Porta C, et al. Angiogenesis inhibitor therapies for advanced renal cell carcinoma: toxicity and treatment patterns in clinical practice from a global medical chart review. Int J Oncol. 2014;44(1):5-16. Available at: http://www.ncbi.nlm.nih.gov/entrez/query.fcgi?cmd=Retrieve\&d $\mathrm{b}=\mathrm{PubMed} \& \mathrm{dopt}=$ Citation\&list_uids=24247547. Accessed March 18, 2014.

25. Schnadig I, Hutson T, Chung H, et al. Sunitinib dosing, toxicity, and outcomes in first-line advanced renal cell carcinoma (aRCC): a U.S. Oncology Network (USON) retrospective study. J Clin Oncol. 2013;30(Suppl):Abstract el5089.

26. Escudier B, Eisen T, Stadler WM, et al. Sorafenib in advanced clear-cell renal-cell carcinoma. N Engl J Med. 2007;356(2):125-34. Available at: http:// www.nejm.org/doi/full/10.1056/NEJMoa060655. Accessed March 18, 2014

27. Motzer RJ, Hutson TE, Tomczak P, et al. Sunitinib versus interferon alfa in metastatic renal-cell carcinoma. N Engl J Med. 2007;356(2):115-24. Available at: http://www.nejm.org/doi/full/10.1056/NEJMoa065044. Accessed March 18, 2014. 
Persistence and Compliance with Pazopanib in Patients with Advanced

Renal Cell Carcinoma Within a U.S. Administrative Claims Database

APPENDIX A NDC and J Codes Used to Identify Previous Therapies in the Previously Treated Cohort

\begin{tabular}{l|l|c}
\hline Drug & \multicolumn{1}{c|}{ NDC Code } & J Code \\
\hline Interferon alfa-2b (Intron A) & $00085-1133-01,00085-1168-01,00085-1235-01,00085-1242-01,00085-1254-01,00085-0571-02$, \\
& $00085-1110-01,00085-0539-01$ & 9214 \\
\hline Interferon alfa-2a & $17089-0456-18$ & 9213 \\
\hline Interleukin & $17089-0454-39,17089-0417-18,17089-0296-18,17089-0346-18,17089-0076-20,17089-0299-18$, \\
& $17089-0235-20,63776-0400-14,63776-0270-14,63776-0100-14,17089-0348-18,63776-0037-14$, \\
& $63776-0347-14,17089-0398-18,17089-0419-23,17089-0416-18,17089-0405-18,17089-0388-18$, \\
& $17089-0389-18,17089-0390-18,17089-0381-18,17089-0383-18,17089-0384-18,17089-0385-18$, \\
& $17089-0386-18,17089-0387-18$ & \\
\hline Sunitinib (Sutent) & $00069-0550-38,00069-0550-30,00069-0770-38,00069-0770-30,00069-0980-38,00069-0980-30$, \\
\hline Sorafenib (Nexavar) & $54569-0598-30$ & \\
\hline Axitinib (Inlyta) & $50419-0488-58$ & \\
\hline Temsirolimus (Torisel) & $00069-0145-01,00069-0151-11$ & \\
\hline Everolimus (Afinitor) & $00008-1179-01,00008-1179-05$ & 9330 \\
\hline Bevacizumab (Avastin) & $00078-0414-20,00078-0415-20,00078-0417-20,00078-0594-51,00078-0594-61,00078-0566-51$, \\
\hline Pazopanib (Votrient) & $00078-0566-61,00078-0567-51,00078-0567-61,00078-0620-51,00078-0620-61$ & 8561 \\
\hline NDC=National Drug Codes. & $0173-0804-09$ & \\
\hline
\end{tabular}


Persistence and Compliance with Pazopanib in Patients with Advanced Renal Cell Carcinoma Within a U.S. Administrative Claims Database

\section{APPENDIX B CPT-4 and ICD-9-CM Codes for Surgeries/Medical Procedures Used to Identify Patients with Evidence of Surgery/Nephrectomy and Risk Factors/Comorbidities}

Surgeries and Medical Procedures

CPT-4 Codes

RCC surgery

\begin{tabular}{l|l}
\hline Nephron-sparing surgery & 50543 \\
\hline
\end{tabular}

\begin{tabular}{l|r}
\hline Thermal ablation & 50593
\end{tabular}

\begin{tabular}{l|c}
\hline Nephrectomy, open & 50220,50225 \\
\hline
\end{tabular}

\begin{tabular}{l|l}
\hline Nephrectomy, open, radical & 50230,37799 \\
\hline
\end{tabular}

\begin{tabular}{l|l}
\hline Nephrectomy, open, with ureterectomy and bladder cuff & 50234,50236 \\
\hline
\end{tabular}

\begin{tabular}{l|l} 
Nephrectomy, laparoscopic, radical & 50545 \\
\hline
\end{tabular}

\begin{tabular}{l|l}
\hline Nephrectomy, laparoscopic & 50546,50548 \\
\hline
\end{tabular}

Dialysis

\begin{tabular}{l|c}
\hline Hemodialysis & $90935-90940$ \\
\hline Miscellaneous dialysis procedures & $90945-90947$ \\
\hline End-stage renal disease services & $90951-90970$ \\
\hline Other dialysis procedures & $90989-90999$ \\
\hline Diagnostic Codes & $\begin{array}{c}\text { ICD-9-CM } \\
\text { Codes }\end{array}$ \\
\hline Malignant neoplasm of kidney, except pelvis & 189.0 \\
\hline Malignant neoplasm of renal pelvis & 189.1 \\
\hline Secondary malignant neoplasm & $196 . x x-199 . x x$ \\
\hline Risk Factors and Comorbidities & $\begin{array}{c}\text { ICD-9-CM } \\
\text { Codes }\end{array}$ \\
\hline Hypertension & $401 . x x-404 . x x$ \\
\hline Kidney abnormalities (e.g., horseshoe kidney) & 753.3 \\
\hline Polycystic kidney disease & $753.1 \mathrm{x}$ \\
\hline von Hippel Lindau disease & 759.6 \\
\hline
\end{tabular}

von Hippel Lindau disease

Classification of Diseases, Ninth Revision, Clinical Modification; RCC = renal cell carcinoma. 


\section{Persistence and Compliance with Pazopanib in Patients with Advanced Renal Cell Carcinoma Within a U.S. Administrative Claims Database}

\section{APPENDIX C Random Forests}

Random forestsa are a powerful statistical classification and regression tree method that uses random bootstrap samples of the original data to produce an ensemble of predictive models. A random forests model can be defined as a combination of decision tree models (tree) where each tree depends on the values of a random vector sampled independently and with the same distribution as other trees that together create the final model. Each of these trees is built from a further random subset of the total predictors that maximize the classification criteria at each node. An estimate of the classification error-rate can be obtained using each of the classification and regression trees to predict the data not in the bootstrap sample ("out-of-the-bag") used to grow the tree then average the out-of-the-bag predictions for the grown set of trees. These out-of-the-bag estimates of the error-rate can be quite accurate if enough trees are developed during the training process. Classification is then performed from the majority of predictions given by the trees in the random forests.

The advantages of using random forests in comparison with other statistical classifiers include applicability when the sample size is relatively small (it can handle even sample sizes of <30), high classification accuracy, novel method of determining variable importance, and the ability to handle multicollinearity among predictor variables. The optimal number of predictors ranked by variable importance can be determined by a cross-validation.

When considering the relationship between a binary outcome (e.g., if $\mathrm{PDC} \geq 80 \% \mathrm{PDC} \geq 80=1$, else $\mathrm{PDC}<80=0$ ) and a continuous predictor (e.g., age), a scatter plot is not the best choice, since it does not show the relationship between a binary outcome and a continuous predictor clearly. However, LOESSb which is derived from the term "locally weighted scatter plot smooth" (sometimes LOcal rEgreSSion), shows the relationship clearly (as shown in Figure 3 of this article). The idea of local regression is that the regression model can be locally approximated by the value of a function in some specified parametric class. Such a local approximation is obtained by fitting a regression surface to the data points within a chosen neighborhood of a point. In the LOESS method, weighted least squares are used to fit linear or quadratic functions of the predictors at the centers of neighborhoods. Such fitting is done at each point at which the regression surface is to be estimated.

areiman L. Random forests. ${ }^{16}$

${ }^{b}$ Cleveland W, Devlin S. Locally weighted regression: an approach to regression analysis by local fitting. ${ }^{17}$ 